\title{
Eddy covariance measurements of water vapor and energy flux over a lake in the Badain Jaran Desert, China
}

\author{
SUN Jie ${ }^{1}$, HU Wenfeng ${ }^{1,2,3}$, WANG Nai'ang ${ }^{1 *}$, ZHAO Liqiang ${ }^{1}$, AN Ran ${ }^{1}$, NING Kai ${ }^{1}$, \\ ZHANG Xunhe ${ }^{1}$ \\ ${ }^{1}$ College of Earth and Environmental Sciences, Center for Desert and Arid Region Research, Lanzhou University, Lanzhou \\ 730000, China; \\ ${ }^{2}$ Center for Central Asian Atmosphere Science Research, Urumqi 830002, China; \\ ${ }^{3}$ Fuyang Normal University, Fuyang 236037, China
}

\begin{abstract}
Exploring the surface energy exchange between atmosphere and water bodies is essential to gain a quantitative understanding of regional climate change, especially for the lakes in the desert. In this study, measurements of energy flux and water vapor were performed over a lake in the Badain Jaran Desert, China from March 2012 to March 2013. The studied lake had about a 2-month frozen period (December and January) and a 10-month open-water period (February-November). Latent heat flux (LE) and sensible heat flux (Hs) acquired using the eddy covariance technique were argued by measurements of longwave and shortwave radiation. Both fluxes of longwave and shortwave radiation showed seasonal dynamics and daily fluctuations during the study period. The reflected solar radiation was much higher in winter than in other seasons. LE exhibited diurnal and seasonal variations. On a daily scale, LE was low in the morning and peaked in the afternoon. From spring (April) to winter (January), the diurnal amplitude of LE decreased slowly. LE was the dominant heat flux throughout the year and consumed most of the energy from the lake. Generally speaking, LE was mostly affected by changes in the ambient wind speed, while Hs was primarily affected by the product of water-air temperature difference and wind speed. The diurnal LE and Hs were negatively correlated in the open-water period. The variations in Hs and LE over the lake were differed from those on the nearby land surface. The mean evaporation rate on the lake was about $4.0 \mathrm{~mm} / \mathrm{d}$ over the entire year, and the cumulative annual evaporation rate was $1445 \mathrm{~mm} / \mathrm{a}$. The cumulative annual evaporation was 10 times larger than the cumulative annual precipitation. Furthermore, the average evaporation rates over the frozen period and open-water period were approximately 0.6 and $5.0 \mathrm{~mm} / \mathrm{d}$, respectively. These results can be used to analyze the water balance and quantify the source of lake water in the Badain Jaran Desert.
\end{abstract}

Keywords: eddy covariance; energy flux; radiation; evaporation; precipitation; lake; Badain Jaran Desert

Citation: SUN Jie, HU Wenfeng, WANG Nai'ang, ZHAO Liqiang, AN Ran, NING Kai, ZHANG Xunhe. 2018. Eddy covariance measurements of water vapor and energy flux over a lake in the Badain Jaran Desert, China. Journal of Arid Land, 10(4): 517-533. https://doi.org/10.1007/s40333-018-0057-3

\section{Introduction}

Lakes cover a large area of the Earth's surface and make vital contributions to regional energy

\footnotetext{
*Corresponding author: WANG Nai'ang (E-mail: wangna@1zu.edu.cn)

Received 2017-06-30; revised 2018-01-31; accepted 2018-02-13

C Xinjiang Institute of Ecology and Geography, Chinese Academy of Sciences, Science Press and Springer-Verlag GmbH Germany, part of Springer Nature 2018
} 
balance and the water cycle. Because the surface energy exchange, with different heat capacity and albedo from those of the surrounding land surface, through biogeochemical and biophysical processes, lakes can affect climate to some extent at both local and regional scales, even at the global scale (Bonan, 1995; Small et al., 1999; Magnuson et al., 2000; Walter et al., 2006; Long et al., 2007; Liu et al., 2012; Lee et al., 2014). Environmental changes, open-water surface hydrological processes, and water-atmosphere system can all have a significant influence on surface energy exchange, and it is important to gain a quantitative understanding of how these factors affect climate and weather (Hostetler and Bartlein, 1990; Bates et al., 1993, 1995; Tsuang et al., 2001; Li et al., 2016). Some previous studies on lakes have found that lakes can act as substantial energy reservoirs that introduce massive seasonal thermal lags in the surrounding landscape due to their large heat capacities of lakes (Blanken et al., 2000; Schertzer et al., 2003; Downing et al., 2006; Nordbo et al., 2011). Intraseasonal surface evaporation and energy radiation of lakes are significant and are closely corrected with strong winds and other weather events (Rouse et al., 2003, 2005; Lenters et al., 2005; Liu et al., 2009; Kettle et al., 2012). However, there have been few studies focusing on the surface evaporation and energy radiation of lakes in regions with strong winds, especially the desert regions.

Eddy covariance (EC) techniques have been widely and successfully used to measure carbon, water and energy fluxes between atmosphere and water bodies, forests and other terrestrial ecosystems (Barford et al., 2001; Xu et al., 2013; Baldocchi, 2014; McGloin et al., 2014; Jung et al., 2017), as well as lakes (Blanken et al., 2000; Liu et al., 2009; Xiao et al., 2013; Biermann et al., 2014). However, few EC measurements have been made over inland lakes; moreover, little or no work has been done on lakes in deserts because of the harsh environment. Meanwhile, it should be noted that the energy flux depends on many aspects, such as lake size, lake depth and surrounding terrain. As a consequence, EC measurements need to be conducted in regions with different climate and weather conditions (Lenters et al., 2005; Liu et al., 2009). Furthermore, the EC observation network needs to be supplemented by studies of lakes in deserts to provide reliable and comprehensive knowledge of energy and water vapor fluxes over different terrains.

The Badain Jaran Desert is one of the driest regions in China. However, more than 110 perennial lakes are distributed among megadunes in its hinterland (Wang et al., 2016). These lakes vary in shape, size and salinity. Previous studies have investigated the geochemistry of the groundwater and lakes (Yang and Williams, 2003; Chen et al., 2004; Gates et al., 2008a, b), the lake-level fluctuations in the past recorded by palaeoshorelines (Yang et al., 2010), the aeolian geomorphology and evolution of megadunes (Yang and Williams, 2003; Zhu et al., 2012; Rioual et al., 2013), and the key scientific problem, namely, the source of lake water (Dong et al., 2016). From the perspective of water balance, the water vapor exchange is an important part of water budget; and from the perspective of energy balance, the lake-atmosphere exchange is a significant part of energy transfer, especially the evaporation of lakes. Accurately quantifying the evaporation of lakes is a particular research challenge, especially in the water-scarce area (Xu et al., 2013; McGloin et al., 2014). Study of the water cycle and energy flux in the Badain Jaran Desert is of great significance for understanding the lake-atmosphere interaction and the source of lake water, as well as for managing water resource.

The aims of this study are quantifying the energy flux over a lake in the Badain Jaran Desert to provide detailed knowledge about the thermal conditions, estimating the evaporation of the lake using EC measurements, and determining the relationships of sensible heat flux (Hs) and latent heat flux (LE) with several environmental factors. This study may fill a gap in the current knowledge of lake-atmosphere interactions over lakes in arid regions, especially in deserts. The results could provide a scientific reference for future studies on the source of lake water.

\section{Materials and methods}

\subsection{Study area}

The Badain Jaran Desert $\left(39^{\circ} 04^{\prime} 15^{\prime \prime}-42^{\circ} 12^{\prime} 23^{\prime \prime} \mathrm{N}, 99^{\circ} 23^{\prime} 18^{\prime \prime}-104^{\circ} 34^{\prime} 02^{\prime \prime} \mathrm{E}\right)$ lies in the western 
part of Inner Mongolia Autonomous Region, China. It is surrounded by the ancient Juyan Lake and Guaizi Lake to the north, the Beida Mountain and Heli Mountain to the south, the ancient Gurinai Lake and the Zhengyi Gorge of the Heihe River to the west, and the Yabrai Mountain to the southeast (Ma et al., 2014). The Badain Jaran Desert has an area of about $52 \times 10^{3} \mathrm{~km}^{2}$ (Zhu et al., 2010). The prevailing wind direction in the interior and surrounding regions of the desert is northwesterly in spring, easterly in summer and autumn, and westerly in winter (Chen, 2011). The wind speed in the northern part of the desert is much greater than that in the southern part of the desert (Yang et al., 2003; Dong et al., 2004). The annual mean wind speed varies from 2.8 to 4.6 $\mathrm{m} / \mathrm{s}$, and the highest wind speed is observed in April and May of each year. The annual mean diurnal temperature is $34.4^{\circ} \mathrm{C}$ (Ma et al., 2014), and the mean temperatures in winter and summer are $-9.1^{\circ} \mathrm{C}$ and $25.3^{\circ} \mathrm{C}$, respectively. The Badain Jaran Desert is therefore classified as a "cold desert" (Warner, 2004). The mean annual precipitation is $90.1-115.4 \mathrm{~mm}$ in the south of the desert and $35.2-42.9 \mathrm{~mm}$ in the north of the desert. Thus, the climate is characterized by a continental arid climate. Shallow groundwater and springs are present around lakes in the desert. The total dissolved solids (TDS) of the springs are less than $1 \mathrm{~g} / \mathrm{L}$. The lakes are primarily located in the southeast of the desert, i.e., on leeward slopes of dunes in the interdune depressions.

Yindeertu Lake, located in the Badain Jaran Desert, is a large lake with a small island far from the shore $\left(39^{\circ} 50^{\prime} \mathrm{N}, 102^{\circ} 27^{\prime} \mathrm{E}\right.$; $1169 \mathrm{~m}$ a.s.l.; Fig. 1). It has a surface area of approximately 1.03 $\mathrm{km}^{2}$. The measured maximum depth is approximately $9.4 \mathrm{~m}$, and the mean depth is about $5.6 \mathrm{~m}$. No runoff has been found over the lake. The TDS content in this lake exhibits significant seasonal variations, ranging from 140 to $220 \mathrm{~g} / \mathrm{L}$. During the study period (March 2012 to March 2013), freeze-up and ice break-up occurred in late December and early March, respectively. The dominant plant species around the lake are Artemisia desterorum and Glycyrrhiza yunnanensis. The lake is surrounded by dunes, with heights ranging from 200 to $300 \mathrm{~m}$. The dunes and lakes in the Badain Jaran Desert are relatively stable and do not move within one year.

\subsection{Experimental measurements}

The eddy covariance (EC) measurement system (E1) was located in the center of the Yindeertu Lake, $250 \mathrm{~m}$ from the nearest shore (Fig. 1c). The space is enough to satisfy the flux measurement for all wind directions. The radiometers were mounted on the water surface beside the EC system. The data for this study were collected from March 2012 to March 2013.

In principle, the EC measurement method provides direct estimates of momentum flux, sensible heat flux (Hs) and latent heat flux (LE). In this study, these turbulent fluxes were measured by an EC system, which included a three-dimensional sonic anemometer (R3-50, GILL, $\mathrm{UK}$ ) and an open-path $\mathrm{CO}_{2} / \mathrm{H}_{2} \mathrm{O}$ infrared gas analyzer (LI-7500A, Li-COR, USA). These instruments were set at the height of $2.3 \mathrm{~m}$ and were separated by a horizontal distance of $20 \mathrm{~cm}$. Wind velocities in three dimensions and atmospheric temperature fluctuations were measured, together with variations in water vapor density. Sensor signals were acquired with a logger (LI-7550, Li-COR, USA) at $10 \mathrm{~Hz}$. Relative humidity and air temperature were obtained using Humicap sensors (HMP155, Vaisala, Finland) installed at the height of $3.0 \mathrm{~m}$ on airtight double-steel radiation shields. The water surface temperature was determined using an infrared radiometer (Apogee, SI-111, USA), which was installed at the height of $1.5 \mathrm{~m}$ above the water surface beside the EC system. The net radiation was obtained through a four-component net radiometer (NR01, Hukseflux, Netherlands) at the height of $1.5 \mathrm{~m}$ above the water surface, as with the infrared radiometer. A tipping-bucket rain gauge (HOBO RG3-M, Onset, USA) installed at the height of $1.5 \mathrm{~m}$ was employed to record the total precipitation at 30-min intervals automatically. Slow-response sensor signals were obtained with a CR-3000 data logger (Campbell Scientific Inc., USA), at an average interval of $30 \mathrm{~min}$. All the sensors were fast-response and small enough to cause no flow disturbances, meeting the requirements for the EC technique (Lorrai et al., 2010; Lemaire et al., 2017).

Another EC measurement system (E2) was located on a nearby flat sandy land on the lower part of a megadune beside Sumubarunjilin, $6.68 \mathrm{~km}$ away from the EC on the lake (E1). This EC system included the same types of instruments as the lake-based EC system (Hu et al., 2015). 

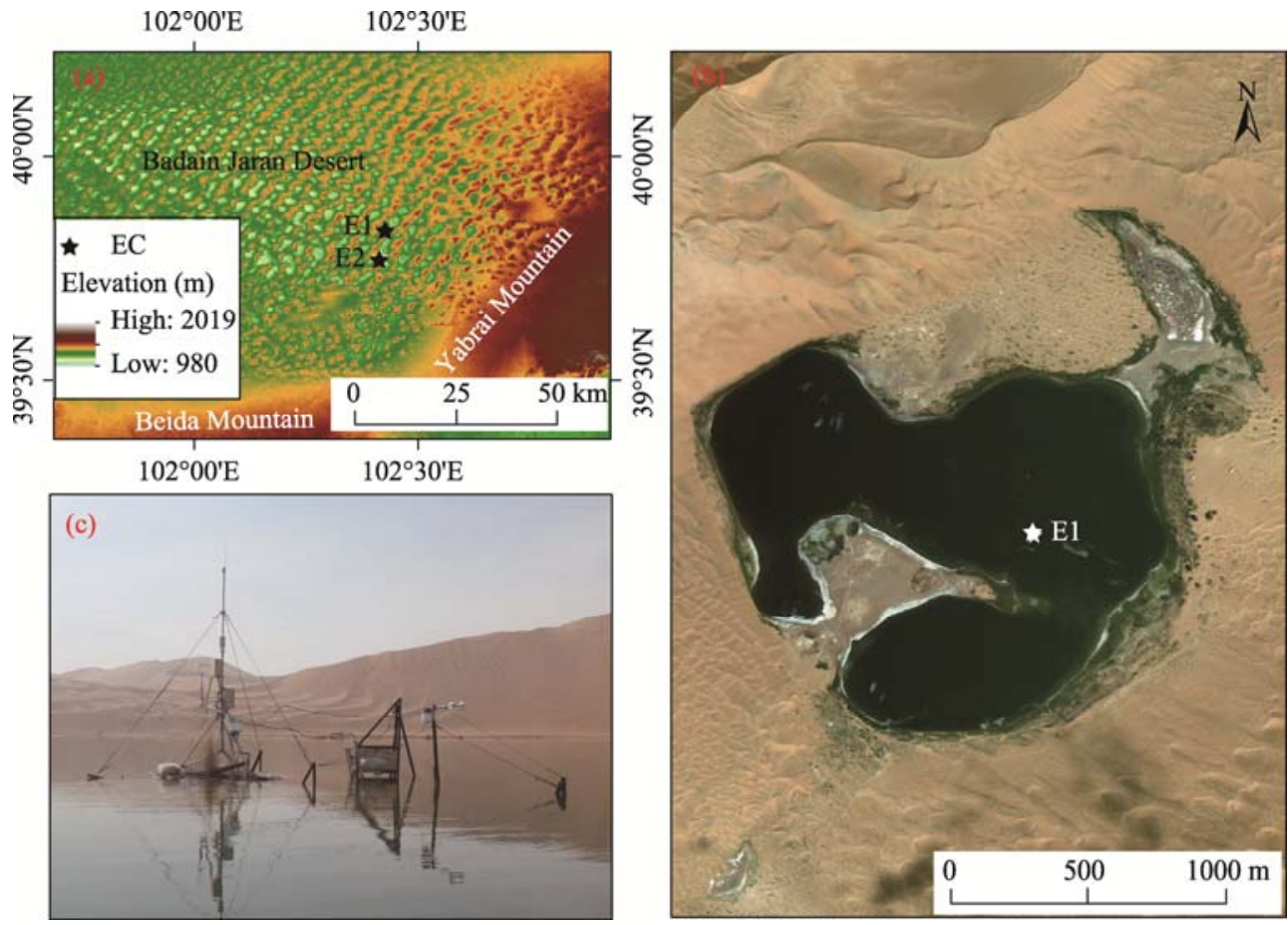

Fig. 1 Distribution of the eddy covariance (EC) instrument on the Yindeertu Lake (E1) and land surface (E2) in the lake group, southeastern Badain Jaran Desert (a), location of the E1 on the Yindeertu Lake (b), and landscape of the Yindeertu Lake in the Badain Jaran Desert (c)

\subsection{Data processing}

The monthly averages of air temperature, water surface temperature, albedo over the lake, wind speed, relative humidity and water vapor density, and the total precipitation were obtained through the EC system.

The values of $\mathrm{Hs}\left(\mathrm{W} / \mathrm{m}^{2}\right)$ and $\mathrm{LE}\left(\mathrm{W} / \mathrm{m}^{2}\right)$ were determined using the EC method as follows (Eqs. 1 and 2, respectively):

$$
\begin{aligned}
& \mathrm{Hs}=\rho_{\alpha} c_{\rho} \overline{w^{\prime} T^{\prime}}, \\
& \mathrm{LE}=\rho_{\alpha} L_{v} \overline{w^{\prime} q^{\prime}},
\end{aligned}
$$

where $\rho_{\alpha}\left(\mathrm{kg} / \mathrm{m}^{3}\right)$ is air density; $\mathrm{c}_{\rho}(\mathrm{J} /(\mathrm{kg} \cdot \mathrm{K}))$ is the specific heat of air at a constant pressure, i.e., $1004 \mathrm{~J} /(\mathrm{kg} \cdot \mathrm{K}) ; L_{v}(\mathrm{~J} / \mathrm{kg})$ is the latent heat of water vapor, which can be obtained with an equation of air temperature (Aubinet et al., 2000); and the parameters $w^{\prime}(\mathrm{m} / \mathrm{s}), T^{\prime}(\mathrm{K})$ and $q^{\prime}(\mathrm{kg} / \mathrm{kg})$ are the deviations from the temporal averages of the vertical wind speed, air temperature and specific humidity, respectively. Furthermore, the overbars in Equations 1 and 2 indicate the time average (over $30 \mathrm{~min}$ in this study).

The component fluxes of the radiation balance were expressed as Equation 3:

$$
\mathrm{Rn}=\mathrm{DR}-\mathrm{UR}-(\mathrm{ULR}-\mathrm{DLR}) \text {, }
$$

where $\mathrm{Rn}, \mathrm{DR}$ and UR are the net all-wave radiation, incident solar radiation and reflected solar radiation, respectively; ULR is the outgoing longwave radiation from the lake surface; and DLR is the incoming longwave sky radiation. The units of all these parameters are $\mathrm{W} / \mathrm{m}^{2}$.

Monthly variations of Rn, DR, UR, DLR, ULR, ULR-DLR, the daily total evaporation rate (ET) and the seasonal and daily variations of LE and Hs were explored, in four months representing different seasons: January (winter), April (spring), July (summer) and October (autumn). Correlation analyses were performed to obtain the driving forces behind heat fluxes. Finally, comparisons of heat fluxes between the lake and land surface, and between evaporation 
and precipitation were obtained.

\subsection{Data quality control and flux footprint analysis of EC}

After periodic calibration and instrument maintenance, the raw data were obtained from the EC system at $10 \mathrm{~Hz}$. These data were calculated using the EddyPro Express post-processing software (Version 6.2, Li-COR, USA) in a recommended manner. All data were processed with a rigorous quality control through a uniform procedure.

The key step of the EC technique involves both calculation and correction. After much debate and examination of the results from field observations, we established standards for data collection, calculation and correction. Specifically, we removed the raw data outliers and applied corrections to the raw data for angle-of-attack errors. These errors were caused by imperfections in the sonic anemometer (Gash and Dolman, 2003; Van der Molen et al., 2004) and were dealt with using Nakai correction functions (Nakai et al., 2006). A double rotation was applied to the outliers (Aubinet et al., 2000). A compensation was used to take account of the time lag between the gas analyzer and sonic anemometer measurements. The average vertical deflection in the wind direction was $-1.1^{\circ}$. The frequency response correction (Moncrieff et al., 2005), sonic temperature correction (Van Dijk et al., 2004) and density fluctuation correction (WPL-correction) (Webb et al., 1980) were applied (Hu et al., 2015). We also carried out a turbulence stationarity test (Foken and Wichura, 1996) and an overall turbulence characteristic test, evaluated the quality of data and divided the data according to the quality level. Furthermore, we determined data that were needed to be interpolated or that were missing. The interpolated data accounted for $29 \%$ of the total samples.

There were several examples of gap filling (Aubinet et al., 2000; Falge et al., 2001; Liu et al., 2013). It should be noted that data recorded during dew events and rainy days were not utilized to avoid errors in the calculation resulting from the presence of liquid water on the sensor window of the $\mathrm{CO}_{2} / \mathrm{H}_{2} \mathrm{O}$. An important thermodynamic factor, i.e., the energy of evaporation, mainly came from the DR, as did Hs and LE. The data on DR were relatively reliable and continuous. Therefore, gaps in daytime data were filled using the relationship between the DR and the measured Hs, LE and ET. In this study, the data gaps were filled by cumulative calculation. If the data were indeed missing for less than $3 \mathrm{~d}$, they were interpolated. In contrast, data missing for more than $3 \mathrm{~d}$ were not interpolated unless there was a need for accumulated data. Data gaps at nights were filled with data from the following and preceding dates by linear interpolation. The half-hourly Hs and LE were finally obtained using the EC method.

It is important to quantify the sampling area of the turbulent flux measurements (Hs and LE), which is also known as the flux footprint and is defined as the upwind area that contributes to the flux. We assessed the flux footprint using the Lagrangian particle dispersion model proposed by Kljun et al. (2004). During the daytime, there was no apparent prevailing wind direction on the lake, although the northerly frequency was relatively large. However, there was an obvious change in prevailing wind direction between day and night: southerly during the daytime and northwesterly during the nighttime. The source areas making the most important contribution over the whole day, during the nighttime and during the daytime were respectively at 40.6, 38.2 and $42.9 \mathrm{~m}$ distances from the EC system. About $70 \%$ of the source areas were at $137.3,138.5$ and $136.2 \mathrm{~m}$ distances from the EC system over the whole day, during the nighttime and during the daytime, respectively. Because the distance from the nearest lake shore was greater than 250 $\mathrm{m}$, these results indicated that the observation conditions substantially met the demands for successful observation of fluxes due to the data were obtained from the lake.

\section{Results}

\subsection{General characteristics of the over-lake meteorology}

The monthly averages of air temperature during the observation period showed that from March 2012 to March 2013, the highest air temperature was found in July 2012, with a monthly average temperature of $27.7^{\circ} \mathrm{C}$, while the lowest air temperature was found in January 2013, with a 
monthly average temperature of $-6.7^{\circ} \mathrm{C}$. The air temperature over the lake was above $0{ }^{\circ} \mathrm{C}$ from March to December and below $0^{\circ} \mathrm{C}$ from December to February next year (Fig. 2a). The maximum $\left(35.5^{\circ} \mathrm{C}\right)$ and minimum $\left(-19.3^{\circ} \mathrm{C}\right)$ half-hourly averages of temperature were found in August and December, respectively (Fig. 2a). Based on the observed surface temperature and albedo over the lake from March 2012 to March 2013, we concluded that the lake had about a 2-month frozen period (December and January). We took these two months (i.e., December and January) as a basis for comparison. When the lake was frozen, the variations in lake surface temperature were quite similar to those in air temperature. The highest and lowest lake surface temperatures were $30.1{ }^{\circ} \mathrm{C}$ and $-13.4^{\circ} \mathrm{C}$, respectively (Fig. 2b). The mean wind speed was $1.7 \mathrm{~m} / \mathrm{s}$ at the height of $2.5 \mathrm{~m}$, and the maximum half-hourly average wind speed was $10.1 \mathrm{~m} / \mathrm{s}$. The wind speed in summer was greater than that in winter (Fig. 2c). The relative humidity was fluctuated during the study period, with the average value of $35.9 \%$ (Fig. 2d). It should be noted that no humidity data were collected in August because of the malfunction of the sensor. The total precipitation was $145 \mathrm{~mm}$ during the study period, with most of them occurring from March to September (Fig. 2e). There was an extreme precipitation event occurred on 20 July 2012 (47 mm precipitation), which was extremely heavy in the desert area.

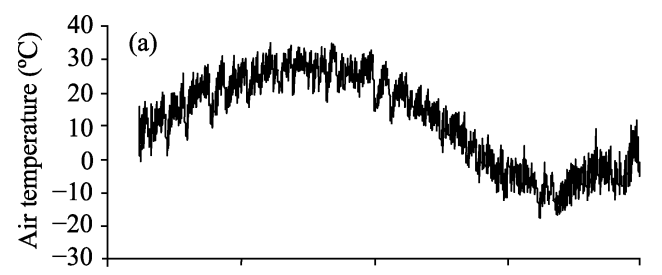

1 Mar 20121 Jun 20121 Sep 20121 Dec 20121 Mar 2013

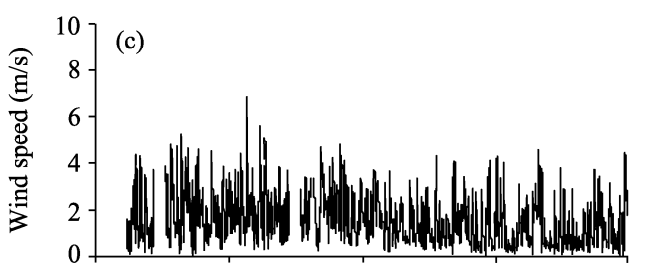

1 Mar 20121 Jun 20121 Sep 20121 Dec 20121 Mar 2013 Date

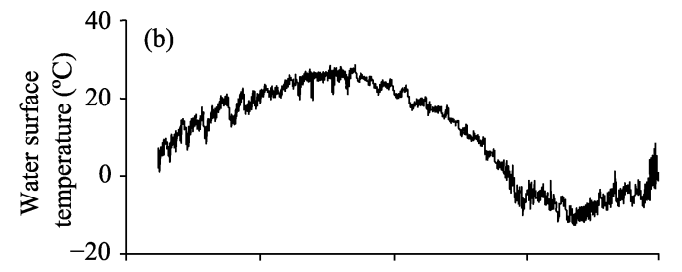

1 Mar 20121 Jun 20121 Sep 20121 Dec 20121 Mar 2013

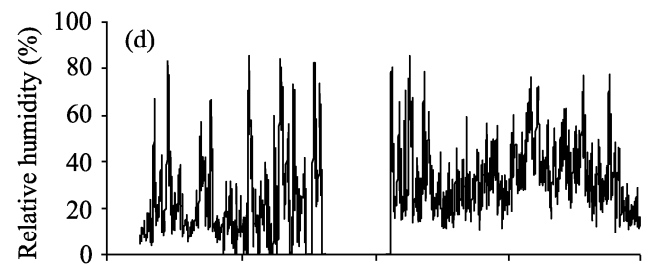

1 Mar 20121 Jun 20121 Sep 20121 Dec 20121 Mar 2013

Date

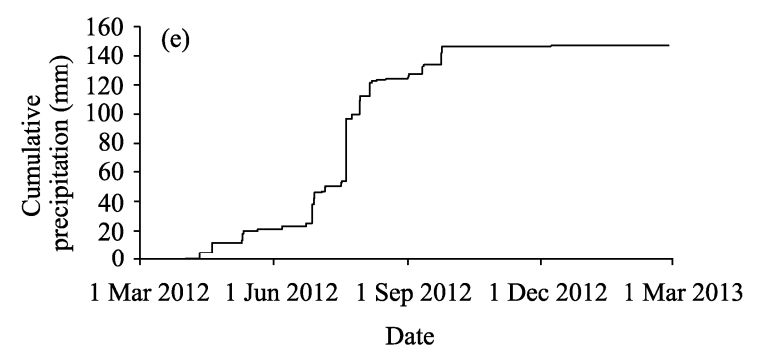

Fig. 2 Half-hourly averages of air temperature (a), water surface temperature (b), wind speed (c) and relative humidity (d), and cumulative precipitation (e) from March 2012 to March 2013. The data of air temperature, water surface temperature, wind speed and relative humidity were smoothed over a 48 -h period. It should be noted that no humidity data were collected in August because of the malfunction of the sensor.

\subsection{Variations in radiation}

Variations of Rn, DR, UR, DLR, ULR, and ULR-DLR from March 2012 to March 2013 are shown in Figure 3. Generally speaking, Rn, DR, DLR and ULR from the lake surface exhibited significant seasonal variations (Figs. 3a, b, d and e). However, UR exhibited a completely different pattern (Fig. 3e). It was significantly higher in January and February than in other months. This may be due to that the amount of UR was closely related to the underlying surface 
conditions. The lake was covered with ice from December 2012 to February 2013. The albedo of the ice surface was much higher than that of the open water. Therefore, the value of UR was high during this period. Note that there was no snow on the lake during the frozen period and thus the albedo was completely from the ice without any contribution of snow.
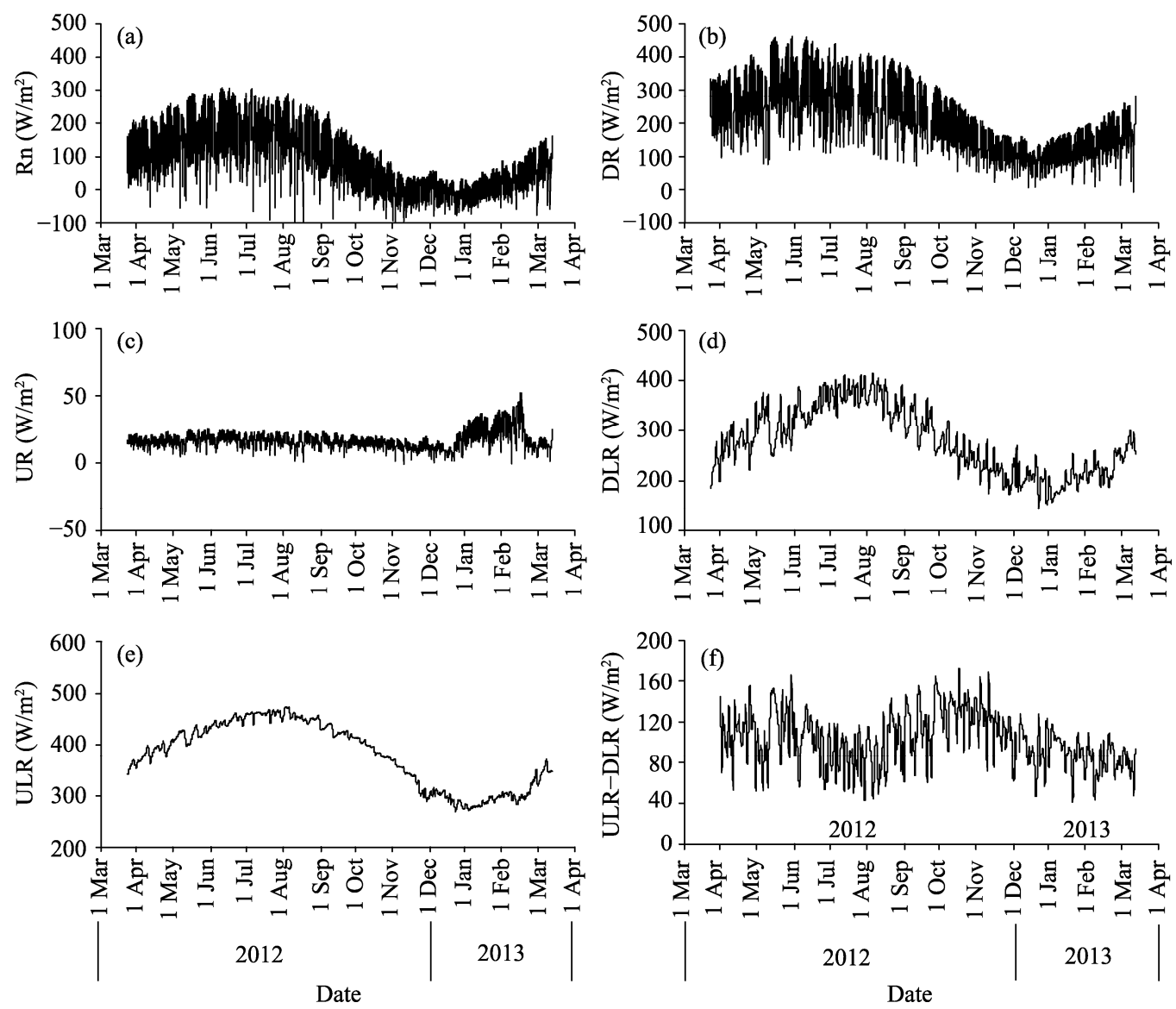

Fig. 3 Variations of net all-wave radiation (Rn, a), solar radiation (DR, b), reflected solar radiation (UR, c), incoming longwave sky radiation (DLR, d), outgoing longwave radiation (ULR, e) and ULR-DLR (f) from March 2012 to March 2013

Seasonal and daily variations in the five types of radiation (including $\mathrm{Rn}, \mathrm{DR}$, UR, DLR and ULR) are presented in Figure 4. The diurnal amplitude of the longwave radiation (i.e., DLR and ULR) was smaller than that of the shortwave radiation (i.e., DR and UR).

The net longwave radiation on the surface of the lake (i.e., ULR-DLR) was always positive during the study period (Fig. 3f), which indicated that the lake continuously lost energy through longwave radiation. The net longwave radiation exhibited two peaks in June and November.

Both shortwave and longwave radiation fluxes showed seasonal dynamics and daily fluctuations; however, they differed specifically at several aspects. DR exhibited smooth and symmetric changes during the day and peaked at solar noon (Fig. 4b), suggesting that clouds are relatively rare in the Badain Jaran Desert. In comparison, the peak value of UR was larger in January than in other months, and UR exhibited more complex and non-symmetric changes in all months with the exception of January (Fig. 4c). The values of ULR and DLR were positive during both the daytime and nighttime, with the daytime values being greater than the nighttime values (Figs. 4d and e). The fluctuations of ULR and DLR were smaller than those of the other types of radiation (including Rn, DR and UR). The variations of Rn were similar to those of DR, with the positive peaks occurring at noon (Figs. $4 a$ and b). Furthermore, the values of Rn were negative at night, and the largest amplitude occurred in midsummer. 
In general, all the radiation values were larger in summer (July) than in winter (January), except for the UR values, which were greater in winter than in summer (Fig. 4). The maximum $\mathrm{Rn}$ and DR values usually occurred during 12:00-14:00 (LST), the maximum UR value appeared at 09:30 in October, and the maximum DLR and ULR values were observed between 15:00 and 18:00.
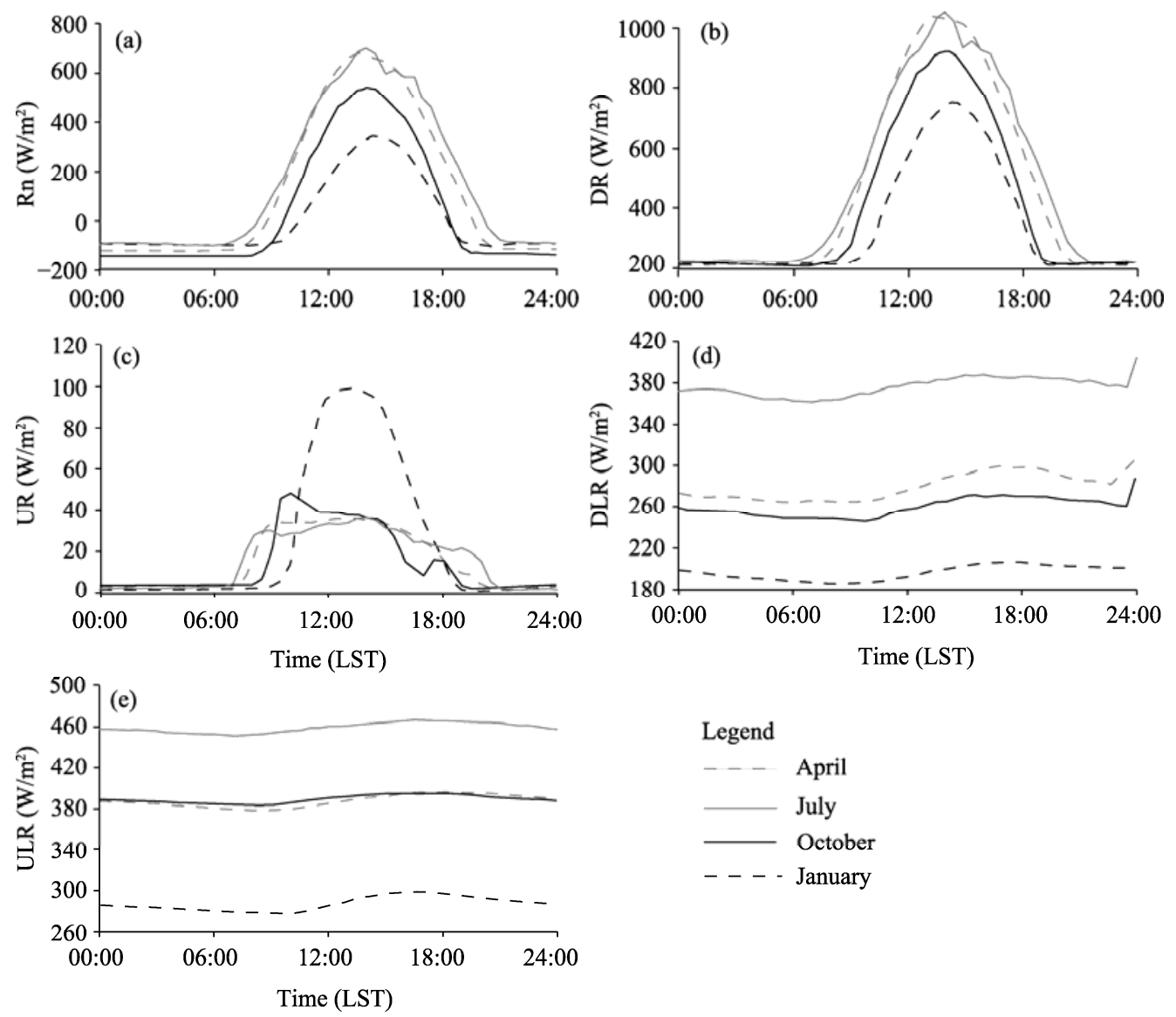

Legend

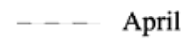

July

October

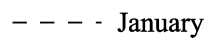

Fig. 4 Seasonal and daily variations of net all-wave radiation ( $\mathrm{Rn}, \mathrm{a})$, solar radiation (DR, b), reflected solar radiation (UR, c), incoming longwave sky radiation (DLR, d) and outgoing longwave radiation (ULR, e) in April, July, October and January

\subsection{Variations in heat fluxes}

During the study period, LE exhibited remarkable seasonal changes, whereas Hs did not show obvious seasonal changes (Fig. 5). LE increased from January to July and decreased from July to January next year. The minimum and maximum values of LE were -25.3 and $799.0 \mathrm{~W} / \mathrm{m}^{2}$, respectively, with an average value of $122.7 \mathrm{~W} / \mathrm{m}^{2}$. The positive LE values mean that heat is lost from the lake via evaporation, while the negative LE values suggest the occurrence of condensation. Over the course of the year, LE was predominantly positive, and negative LE only occurred occasionally in winter. The average Hs was $5.7 \mathrm{~W} / \mathrm{m}^{2}$, which was much smaller than the average LE. Hs varied slightly throughout the year, with large values being observed in winter.

Compared to Hs, LE exhibited clear seasonal and diurnal variations (Fig. 6). On a daily scale, LE was low in the morning and peaked in the afternoon, whereas the maximum Hs occurred in the morning and the minimum Hs occurred in the afternoon or the evening. The results suggested that the available energy was primarily consumed by latent heating in the afternoon and by sensible heating in the morning. From spring (April) to winter (January), the diurnal amplitude of LE decreased slowly, while the changes in the diurnal amplitude of Hs varied slightly. Rn 


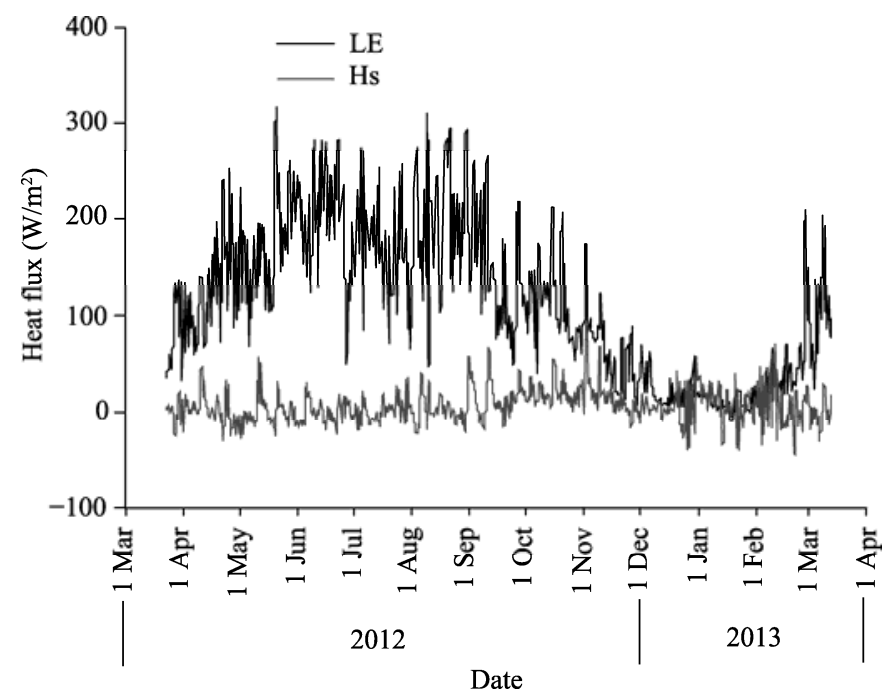

Fig. 5 Variations of sensible heat flux (Hs) and latent heat flux (LE) from March 2012 to March 2013
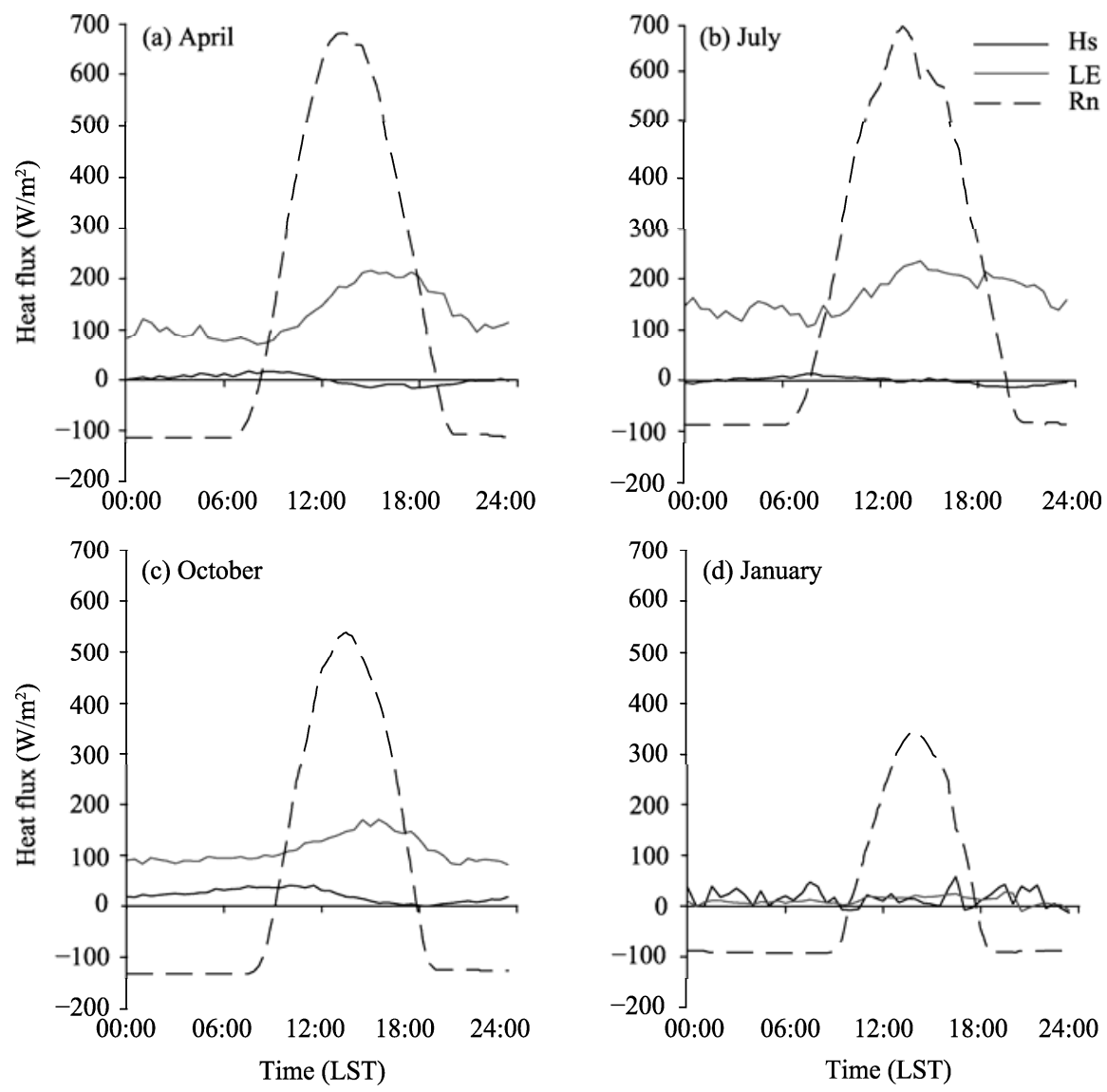

Fig. 6 Seasonal and daily variations of sensible heat flux (Hs), latent heat flux (LE) and net all-wave radiation (Rn) in April (a), July (b), October (c) and January (d)

exhibited obvious difference between the daytime and nighttime periods, with the values being positive during the daytime and negative during the nighttime. The loss of Rn was mainly via the LE throughout the year (except for winter). Rn might be influenced by wind in spring and autumn and by solar radiation in summer. 
As shown in Figure 7a, the daily total ET peaked in summer. From 1 April 2012 to 31 March 2013, the maximum ET was $11.74 \mathrm{~mm} / \mathrm{d}$ in June, and the mean ET was about $4.0 \mathrm{~mm} / \mathrm{d}$. Furthermore, the average ET was approximately $0.6 \mathrm{~mm} / \mathrm{d}$ during the frozen period (December and January) and $5.0 \mathrm{~mm} / \mathrm{d}$ during the open-water period (February-November). Approximately $40 \%$ and $60 \%$ of evaporation occurred during the nighttime and daytime, respectively. Moreover, ET generally decreased throughout late summer and autumn. It maintained relatively low values from December to January and increased from March to June. The average ET was lower in July than in June and August. It should be noted that the maximum ET did not occur in July, although the temperature was highest in this month. The cumulative evaporation was $1445 \mathrm{~mm}$ from 1 April 2012 to 31 March 2013 (Fig. 7b), which was 10 times larger than the accumulated precipitation over the same period.
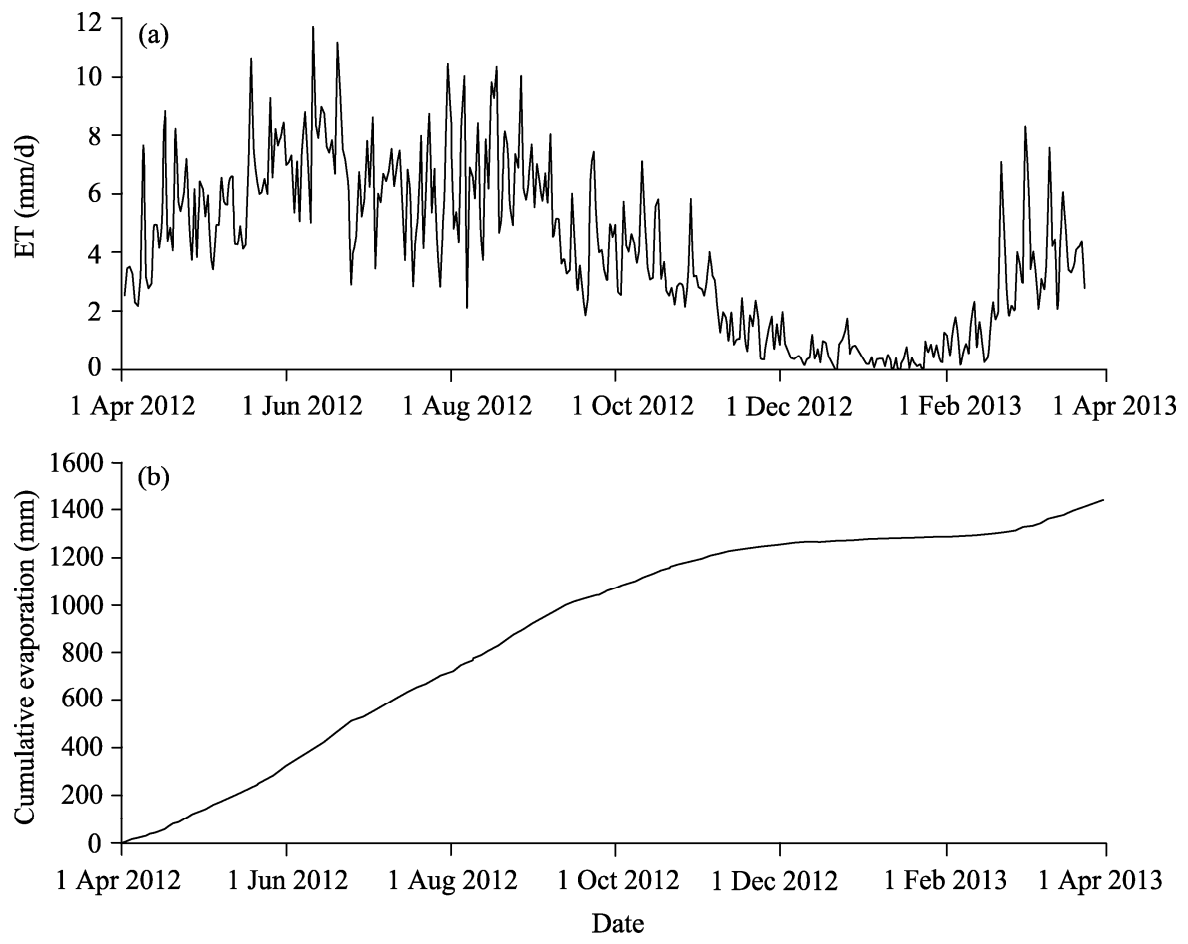

Fig. 7 Daily total evaporation rate (ET, a) and cumulative evaporation (b) from 1 April 2012 to 31 March 2013

\section{Discussion}

\subsection{Radiation and heat fluxes}

Annual variations in DR were largely affected by solar elevation and weather conditions, including reflection, scattering and absorption due to ambient atmospheric conditions. Monthly variations in DR were due to the changes in the azimuthal angle of the sun, while daily variations were due to the effects of clouds. The UR was determined mainly by the features of the underlying surface conditions, particularly the albedo. The studied lake was frozen in winter (January), and the albedo was higher in winter than in other seasons. Therefore, UR was relatively large in winter (Fig. 4c). The diurnal curve of the albedo was not symmetric. This may be due to the highly variable sand hills surrounding the lake, which tended to block incident UR. The monthly average albedo was 0.13 from March to November; however, it was 0.21 from December to February, which is greater than the value (i.e., 0.07) reported for a water reservoir in a semi-arid region (Gallego-Elvira et al., 2010) but smaller than the value in an alpine meadow or a savanna (Beringer and Tapper, 2002; Al-Riahi et al., 2003; Berbert and Costa, 2003; Zhang et al., 2010). However, the albedos obtained in this study are similar to the average values of the Earth 
and the Northern Hemisphere (Gupta et al., 1999). This suggests that the energy loss from the lake ecosystem via radiation may be lower than the loss from other ecosystems because of the relatively low albedo.

The exchange of longwave radiation between atmosphere and lake surface is controlled primarily by surface features, clouds, atmospheric temperature, and atmospheric water vapor pressure. Over the studied lake, the water vapor pressure varied from 0.1 to $2.0 \mathrm{KPa}$ (Fig. 8). However, it was previously reported that the water vapor pressure in most ecosystems typically varied from 2.0 to $5.0 \mathrm{KPa}$ (Kellner, 2001; Hunt et al., 2002; Wever et al., 2002). The water vapor pressure in the studied desert lake ecosystem was slightly higher than that in the deserts (ranging from 0.01 to $1.5 \mathrm{KPa}$ ) and much smaller than that in most other ecosystems. Because of the low ambient water vapor pressure and relatively few clouds, DLR over the studied lake was obviously lower than the value given by NASA for the Earth as a whole (Gupta et al., 1999).
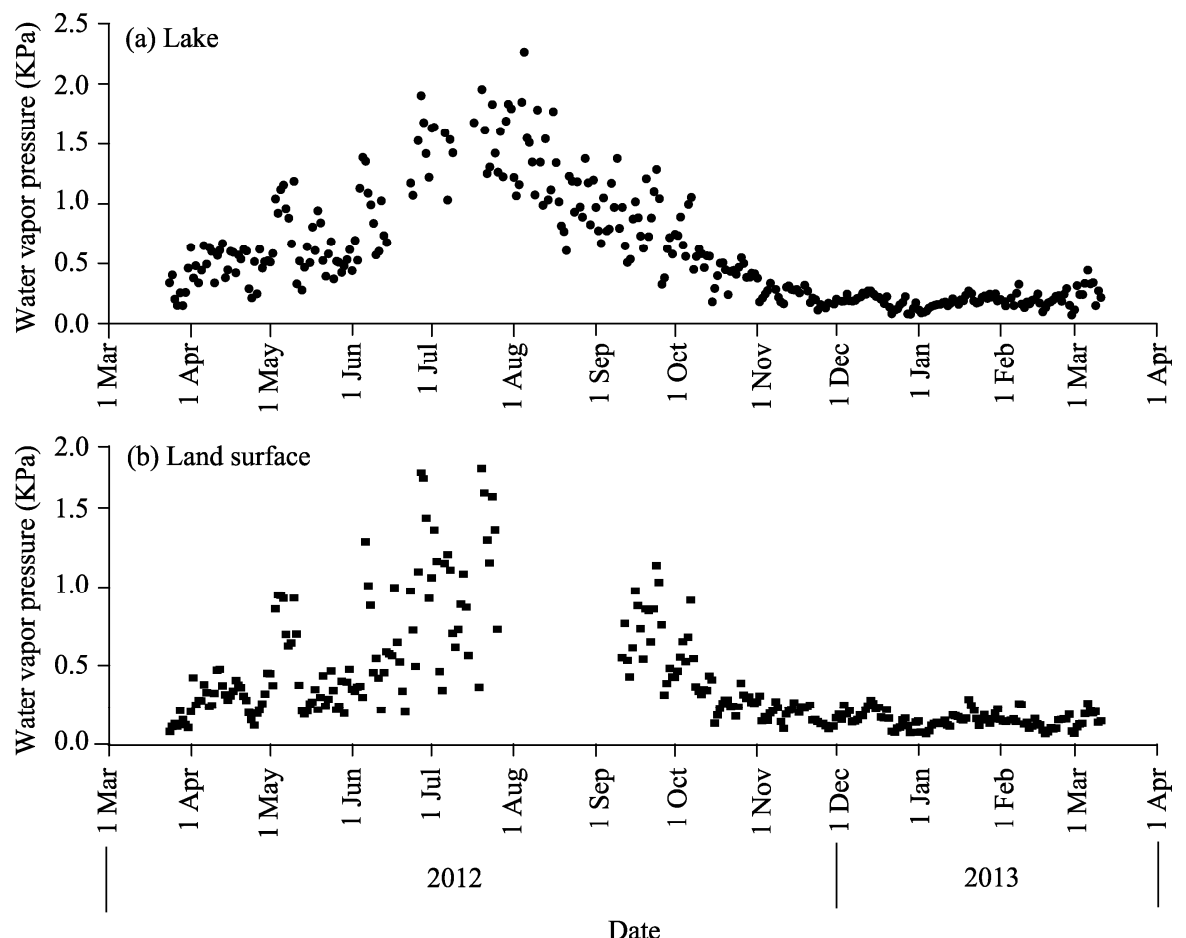

Fig. 8 Variations in water vapor pressure over the lake (a) and the surrounding land (desert) surface (b) from March 2012 to March 2013

The diurnal amplitude of LE was smaller in winter and larger in spring, which indicated that the ice cover effectively restricted the heat exchange between air and water. Simultaneously, the ice cover significantly increased the surface albedo and reduced the absorbed incident shortwave radiation.

\subsection{Driving forces behind heat fluxes}

Turbulent exchanges of water vapor and heat flux over lakes are affected by the surrounding environment. The heat flux over a lake surface is determined mainly by the ambient temperature, turbulent mixing intensity, and water-air vapor pressure deficit (Hostetler and Bartlein, 1990; Bonan, 1995; Liu et al., 2009; Nordbo et al., 2011). The air at the interface between the lake and the overlying atmosphere is always saturated, and the saturation pressure is a function of the lake surface temperature at the interface (Hostetler and Bartlein, 1990). Meanwhile, several other parameterizations have been proposed, especially for lake evaporation (Rosenberry et al., 2007).

After calculating the relationship between $\mathrm{Hs}$ and LE by taking account of several environmental factors (Fig. 9), we draw similar conclusions as provided by previous studies. 
Specifically, there were obvious correspondences between $\mathrm{Hs}$ and water-air temperature difference (Nordbo et al., 2011; Liu et al. 2015), between Hs and wind speed $\times$ water-air temperature difference (Blanken et al., 2000, 2003; Liu et al., 2009; Nordbo et al., 2011), between LE and wind speed (Liu et al., 2009), and between LE and wind speed $\times$ water-air vapor pressure deficit (Blanken et al., 2003; Liu et al., 2009; Nordbo et al., 2011). According to the study of Blanken et al. (2000), LE could be better described by wind speed $\times$ water-air vapor pressure deficit than by water-air vapor pressure deficit alone at Great Slave Lake. Taking account of the influence of wind on latent heat and evaporation, we analyzed the correlations of LE with wind speed and wind speed $\times$ water-air vapor pressure deficit. We then turned to correlation analyses of Hs and water-air temperature difference, $\mathrm{Hs}$ and wind speed $\times$ water-air temperature difference, LE and wind speed, and LE and wind speed $\times$ water-air vapor pressure deficit for further explanation (Fig. 9). Our results suggest that water-air temperature difference explained $45 \%$ of the variation in Hs. Moreover, the product of water-air temperature difference and wind speed explained 55\% of the Hs variability. In contrast, about $49 \%$ of the variation in LE could be explained by changes in wind speed, and $48 \%$ of the variation in LE was explained by the product of water-air vapor pressure deficit and wind speed. Our results were similar to the findings of Nordbo et al. (2011) but opposite with the conclusions of Liu et al. (2009). The reason for the difference is that the lake in the study of Liu et al. (2009) is located in a humid coastal area whereas the lake in this study is situated in an arid desert. The complex conditions of terrain can produce advection (Kaimal and Finnigan, 1994). According to our observations, the atmosphere over the lake exhibited a pronounced inversion layer, with lake-breeze circulations. This implies that the horizontal transport of latent heat cannot be ignored in arid regions. Meanwhile, salinity could affect the heat exchange between lake and atmosphere, while groundwater (temperature of $18^{\circ} \mathrm{C}$ in the study period) recharge supplies a large amount of heat. Therefore, LE and Hs exhibited weak run-to-run relationships with the environmental factors $\left(R^{2}<0.50\right)$.
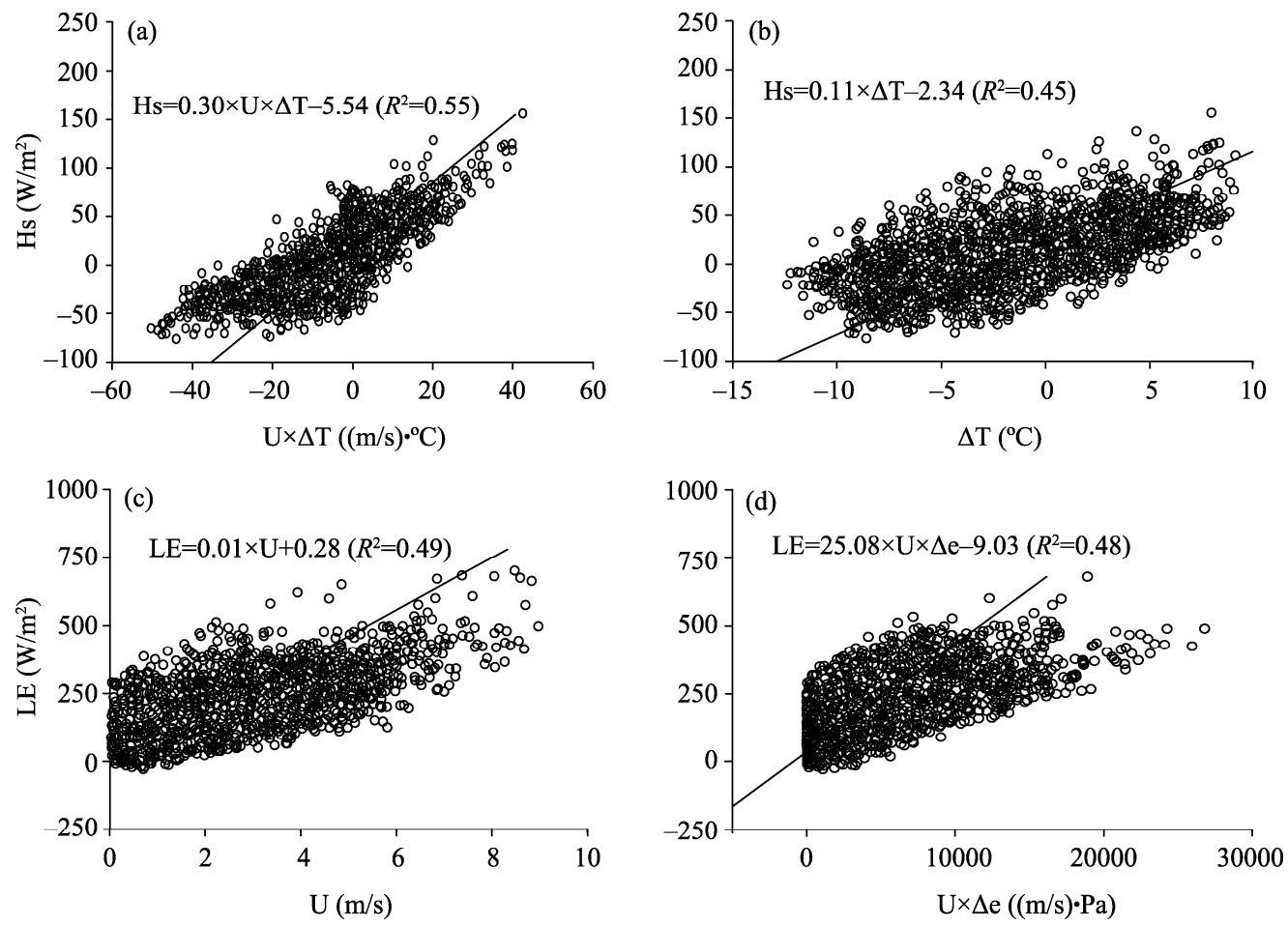

Fig. 9 Relationships between half-hourly Hs and $U \times \Delta T$ (a), Hs and $\Delta \mathrm{T}$ (b), LE and $U$ (c), and LE and $U \times \Delta e$ (d). Hs, sensible heat flux; $\Delta \mathrm{T}$, water-atmosphere temperature difference; $\mathrm{U}$, wind speed; LE, latent heat flux; $\Delta \mathrm{e}$, water-air vapor pressure deficit.

Several previous studies have shown that the heat fluxes are sensitive to $\mathrm{Rn}$, vapor pressure 
deficit of atmosphere-lake system and aerodynamic conductance (Williams et al., 1998; Malhi et al., 2002; Vourlitis et al., 2002; Kumagai et al., 2005; Loescher et al., 2005; Nordbo et al., 2011; Pan et al., 2017), whereas other studies have indicated that the measured LE values are not sensitive to these environmental factors (Blanken et al., 2000; Loescher et al., 2005; Liu et al., 2009). The differences are due to the presence of vegetated surfaces where stomatal conductance control is high.

\subsection{Comparison of heat fluxes between lake and land surface}

The variations in Hs and LE observed by the EC system on the nearby land surface (Hu et al., 2015) were differed from those observed on the lake surface. On the land surface, Hs is strong and LE is weak (Hu et al., 2015), whereas on the lake surface, Hs is weak and LE is strong (Fig. 5). There is a negative correlation between the changes in Hs and LE. In the desert hinterland, LE could become negative at times during the year even over the lake, indicating that the latent heat is transported downward. This phenomenon has also been observed in other deserts (Wang and Mitsuta, 1990, 1992; Harazono et al., 1992). The reason may be due to that the air on the lake flows by advection across the dry land and the water vapor flux is in a downward direction on the land, implying a downward delivery of water vapor. On the land surface, there were obvious changes in Hs during the year (Hu et al., 2015). Specifically, from March to November, Hs was mainly positive, meaning that the heat was transferred to the atmosphere. However, from November to March, Hs changed dramatically, with a large number of negative values occurring. This indicated that the heat was transferred from the atmosphere to the land surface. On the lake surface, LE was occasionally negative, implying a downward delivery of water vapor.

\subsection{Evaporation}

The ET values observed on Yindeertu Lake of the Badain Jaran Desert exceeded those observed on high-latitude lakes (Schertzer et al., 2000; Rouse et al., 2003; Oswald and Rouse, 2004) but were similar to those measured in semi-arid reservoirs (Gallego-Elvira et al., 2010). The average ET was $0.6 \mathrm{~mm} / \mathrm{d}$ during the frozen period for Yindeertu Lake, which is smaller than the previously simulated ET (1.3-1.4 mm/d) for Lahontan Lake (Hostetler, 1991). This difference might be due to the similar latitude but different longitudes between the two lakes. Furthermore, the atmosphere over the lake in our study was unstable at night. As a result, a strong lake-breeze circulation formed, which increased the evaporation (accounting for $40 \%$ of the total evaporation). Because the net solar radiation and water-air vapor pressure deficit are large in the desert and are coupled to dry air, evaporation is strong in the desert areas (Zhu et al., 2012). However, ET from the lake surface measured in this study is much smaller than those estimated by Chen et al. (2004) and Gates et al. (2008a, b). Note that the net evaporation is 10 times larger than the precipitation in the study area, indicating that the lake is supplied mainly by groundwater during the study period.

\section{Conclusions}

This study measured the radiation components, evaporation rates and heat fluxes by an EC system from March 2012 to March 2013 over a lake in the Badain Jaran Desert, China. Both shortwave and longwave radiation exhibited seasonal dynamics and large fluctuations. LE exhibited both seasonal variations and diurnal dynamics. LE was mainly affected by the changes in wind speed, while Hs was primarily affected by the product of water-air temperature difference and wind speed. The diurnal LE and Hs were negatively correlated in the open-water period, and the effective energy of the lake was mainly directed into LE. Generally speaking, LE was the dominant heat flux throughout the year. The average turbulent heat flux over the lake surface was greater than the net solar radiation received by the lake, indicating that other energy supplies to the lake cannot be ignored. LE showed negative values occasionally both on the land surface and lake surface, implying a downward delivery of water vapor. The cumulative evaporation was $1445 \mathrm{~mm} / \mathrm{a}$, and the mean evaporation rate was about $4.0 \mathrm{~mm} / \mathrm{d}$. The total evaporation was 10 
times greater than the total precipitation, indicating that the lake was supplied mainly by groundwater during the study period. Continuous and long-term EC measurements will be needed to allow an interannual analysis to be performed in the future.

\section{Acknowledgements}

This research was supported by the National Natural Science Foundation of China (41530745), the Central Asia Atmospheric Science Research Fund (CAAS201703) and the Fundamental Research Funds for the Central Universities (lzujbky-2016-267). We thank NIU Zhenmin, ZHANG Zhenyu, SHEN Shiping, MA Ning and many other people in the Center for Desert and Arid Region Research, Lanzhou University for their contribution to the field work. We are grateful to the reviewers for their valuable comments on this manuscript.

\section{References}

Al-Riahi M, Al-Jumaily K, Kamies I. 2003. Measurements of net radiation and its components in semi-arid climate of Baghdad. Energy Conversion and Management, 44(4): 509-525.

Aubinet M, Grelle A, Ibrom A, et al. 2000. Estimates of the annual net carbon and water exchange of forests: The EUROFLUX methodology. Advances in Ecological Research, 30: 113-175.

Baldocchi D. 2014. Measuring fluxes of trace gases and energy between ecosystems and the atmosphere-the state and future of the eddy covariance method. Global Change Biology, 20(12): 3600-3609.

Barford C C, Wofsy S C, Goulden M L, et al. 2001. Factors controlling long-and short-term sequestration of atmospheric $\mathrm{CO}_{2}$ in a mid-latitude forest. Science, 294(5547): 1688-1691.

Bates G T, Giorgi F, Hostetler S W. 1993. Toward the simulation of the effects of the great lakes on regional climate. Monthly Weather Review, 121(5): 1373-1387.

Bates G T, Hostetler S W, Giorgi F. 1995. Two-year simulation of the great lakes region with a coupled modeling system. Monthly Weather Review, 123(5): 1505-1522.

Berbert M L C, Costa M H. 2003. Climate change after tropical deforestation: Seasonal variability of surface albedo and its effects on precipitation change. Journal of Climate, 16(12): 2099-2104.

Beringer J, Tapper N. 2002. Surface energy exchanges and interactions with thunderstorms during the Maritime Continent Thunderstorm Experiment (MCTEX). Journal of Geophysical Research: Atmospheres, 107(D21): AAC 3-1-AAC 3-13.

Biermann T, Babel W, Ma W Q, et al. 2014. Turbulent flux observations and modelling over a shallow lake and a wet grassland in the Nam Co basin, Tibetan Plateau. Theoretical and Applied Climatology, 116(1-2): 301-316.

Blanken P D, Rouse W R, Culf A D, et al. 2000. Eddy covariance measurements of evaporation from Great Slave Lake, Northwest Territories, Canada. Water Resources Research, 36(4): 1069-1077.

Blanken P D, Rouse W R, Schertzer W M. 2003. Enhancement of evaporation from a large northern lake by the entrainment of warm, dry air. Journal of Hydrometeorology, 4(4): 680-693.

Bonan G B. 1995. Sensitivity of a gcm simulation to inclusion of inland water surfaces. Journal of Climate, 8(11): $2691-2704$.

Chen H B. 2011. Weather monitoring and preliminary study of climate feature in the Badain Jaran Desert. MSc Thesis. Lanzhou: Lanzhou University. (in Chinese)

Chen J S, Li L, Wang J Y, et al. 2004. Water resources: Groundwater maintains dune landscape. Nature, 432(7016): 459-460.

Dong C Y, Wang N A, Chen J S, et al. 2016. New observational and experimental evidence for the recharge mechanism of the lake group in the Alxa Desert, north-central China. Journal of Arid Environments, 124: 48-61.

Dong Z B, Wang T, Wang X M. 2004. Geomorphology of the megadunes in the Badain Jaran Desert. Geomorphology, 60(1-2): 191-203.

Downing J A, Prairie Y T, Cole J J, et al. 2006. The global abundance and size distribution of lakes, ponds, and impoundments. Limnology and Oceanography, 51(5): 2388-2397.

Falge E, Baldocchi D, Olson R, et al. 2001. Gap filling strategies for defensible annual sums of net ecosystem exchange. Agricultural and Forest Meteorology, 107(1): 43-69.

Foken T, Wichura B. 1996. Tools for quality assessment of surface-based flux measurements. Agricultural and Forest Meteorology, 78(1-2): 83-105.

Gallego-Elvira B, Baille A, Martín-Górriz B, et al. 2010. Energy balance and evaporation loss of an agricultural reservoir in a semi-arid climate (south-eastern Spain). Hydrological Processes, 24(6): 758-766.

Gash J H C, Dolman A J. 2003. Sonic anemometer (co)sine response and flux measurement I. The potential for (co)sine error to 
affect sonic anemometer-based flux measurements. Agricultural and Forest Meteorology, 119(3-4): 195-207.

Gates J B, Edmunds W M, Darling W G, et al. 2008a. Conceptual model of recharge to southeastern Badain Jaran Desert groundwater and lakes from environmental tracers. Applied Geochemistry, 23(12): 3519-3534.

Gates J B, Edmunds W M, Ma J Z, et al. 2008b. Estimating groundwater recharge in a cold desert environment in northern China using chloride. Hydrogeology Journal, 16(5): 893-910.

Gupta S K, Ritchey N A, Wilber A C, et al. 1999. A climatology of surface radiation budget derived from satellite data. Journal of Climate, 12(8): 2691-2710.

Harazono Y, Shen J Y, Liu S M, et al. 1992. Micrometeorological characteristics of a sand dune in the eastern part of Inner Mongolia, China in Autumn. Journal of Agricultural Meteorology, 47(4): 217-224.

Hostetler S W, Bartlein P J. 1990. Simulation of lake evaporation with application to modeling lake level variations of Harney-Malheur Lake, Oregon. Water Resources Research, 26(10): 2603-2612.

Hostetler S W. 1991. Simulation of lake ice and its effect on the late-Pleistocene evaporation rate of Lake Lahontan. Climate Dynamics, 6(1): 43-48.

Hu W F, Wang N A, Zhao L Q, et al. 2015. Surface energy and water vapor fluxes observed on a megadune in the Badain Jaran Desert, China. Journal of Arid Land, 7(5): 579-589.

Hunt J E, Kelliher F M, McSeveny T M, et al. 2002. Evaporation and carbon dioxide exchange between the atmosphere and a tussock grassland during a summer drought. Agricultural and Forest Meteorology, 111(1): 65-82.

Jung M, Reichstein M, Schwalm C R, et al. 2017. Compensatory water effects link yearly global land $\mathrm{CO}_{2}$ sink changes to temperature. Nature, 541(7638): 516-520.

Kaimal J C, Finnigan J J. 1994. Atmospheric Boundary Layer Flows: Their Structure and Measurement. Oxford: Oxford University Press, 1-65.

Kellner E. 2001. Surface energy fluxes and control of evapotranspiration from a Swedish Sphagnum mire. Agricultural and Forest Meteorology, 110(2): 101-123.

Kettle A J, Hughes C, Unazi G A, et al. 2012. Role of groundwater exchange on the energy budget and seasonal stratification of a shallow temperate lake. Journal of Hydrology, 470-471: 12-27.

Kljun N, Calanca P, Rotach M W, et al. 2004. A simple parameterisation for flux footprint predictions. Boundary-Layer Meteorology, 112(3): 503-523.

Kumagai T, Saitoh T M, Sato Y, et al. 2005. Annual water balance and seasonality of evapotranspiration in a Bornean tropical rainforest. Agricultural and Forest Meteorology, 128(1-2): 81-92.

Lee X, Liu S D, Xiao W, et al. 2014. The Taihu Eddy Flux Network: an observational program on energy, water, and greenhouse gas fluxes of a large freshwater lake. Bulletin of the American Meteorological Society, 95(10): 1583-1594.

Lemaire B J, Noss C, Lorke A. 2017. Toward relaxed eddy accumulation measurements of sediment-water exchange in aquatic ecosystems. Geophysical Research Letters, 44(17): 8901-8909.

Lenters J D, Kratz T K, Bowser C J. 2005. Effects of climate variability on lake evaporation: Results from a long-term energy budget study of Sparkling Lake, northern Wisconsin (USA). Journal of Hydrology, 308(1-4): 168-195.

Li X Y, Ma Y J, Huang Y M, et al. 2016. Evaporation and surface energy budget over the largest high-altitude saline lake on the Qinghai-Tibet Plateau. Journal of Geophysical Research: Atmospheres, 121(8): 10470-10485.

Liu H P, Zhang Y, Liu S H, et al. 2009. Eddy covariance measurements of surface energy budget and evaporation in a cool season over southern open water in Mississippi. Journal of Geophysical Research: Atmospheres, 114(D4): D04110.

Liu H P, Zhang Q Y, Dowler G. 2012. Environmental controls on the surface energy budget over a large southern inland water in the United States: An analysis of one-year eddy covariance flux data. Journal of Hydrometeorology, 13(6): 1893-1910.

Liu H Z, Feng J W, Sun J H, et al. 2015. Eddy covariance measurements of water vapor and $\mathrm{CO}_{2}$ fluxes above the Erhai Lake. Science China Earth Sciences, 58(3): 317-328.

Liu S M, Xu Z W, Zhu Z L, et al. 2013. Measurements of evapotranspiration from eddy-covariance systems and large aperture scintillometers in the Hai River Basin, China. Journal of Hydrology, 487: 24-38.

Loescher H W, Gholz H L, Jacobs J M, et al. 2005. Energy dynamics and modeled evapotranspiration from a wet tropical forest in Costa Rica. Journal of Hydrology, 315(1-4): 274-294.

Long Z, Perrie W, Gyakum J, et al. 2007. Northern lake impacts on local seasonal climate. Journal of Hydrometeorology, 8(4): 881-896.

Lorrai C, McGinnis D F, Berg P, et al. 2010. Application of oxygen eddy correlation in aquatic systems. Journal of Atmospheric and Oceanic Technology, 27(9): 1533-1546.

Ma N, Wang N A, Zhao L Q, et al. 2014. Observation of mega-dune evaporation after various rain events in the hinterland of 
Badain Jaran Desert, China. Chinese Science Bulletin, 59(2): 162-170.

Magnuson J J, Robertson D M, Benson B J, et al. 2000. Historical trends in lake and river ice cover in the Northern Hemisphere. Science, 289(5485): 1743-1746.

Malhi Y, Pegoraro E, Nobre A D, et al. 2002. Energy and water dynamics of a central Amazonian rain forest. Journal of Geophysical Research: Atmospheres, 107(D20), doi: 10.1029/2001JD000623.

McGloin R, McGowan H, McJannet D, et al. 2014. Quantification of surface energy fluxes from a small water body using scintillometry and eddy covariance. Water Resources Research, 50(1): 494-513.

Moncrieff J, Clement R, Finnigan J, et al. 2005. Averaging, detrending, and filtering of eddy covariance time series. In: Lee X, Massman W, Law B. Handbook of Micrometeorology: A Guide for Surface Flux Measurement and Analysis. Dordrecht: Springer, 7-31.

Nakai T, van der Molen M K, Gash J H C, et al. 2006. Correction of sonic anemometer angle of attack errors. Agricultural and Forest Meteorology, 136(1-2): 19-30.

Nordbo A, Launiainen S, Mammarella I, et al. 2011. Long-term energy flux measurements and energy balance over a small boreal lake using eddy covariance technique. Journal of Geophysical Research: Atmospheres, 116(D2): D02119.

Oswald C J, Rouse W R. 2004. Thermal characteristics and energy balance of various-size Canadian Shield lakes in the Mackenzie River basin. Journal of Hydrometeorology, 5(1): 129-144.

Pan X, Liu Y B, Fan X W, et al. 2017. Two energy balance closure approaches: applications and comparisons over an oasis-desert ecotone. Journal of Arid Land, 9(1): 51-64.

Rioual P, Lu Y B, Yang H D, et al. 2013. Diatom-environment relationships and a transfer function for conductivity in lakes of the Badain Jaran Desert, Inner Mongolia, China. Journal of Paleolimnology, 50(2): 207-229.

Rosenberry D O, Winter T C, Buso D C, et al. 2007. Comparison of 15 evaporation methods applied to a small mountain lake in the northeastern USA. Journal of Hydrology, 340(3-4): 149-166.

Rouse W R, Oswald C M, Binyamin J, et al. 2003. Interannual and seasonal variability of the surface energy balance and temperature of central Great Slave Lake. Journal of Hydrometeorology, 4(4): 720-730.

Rouse W R, Oswald C J, Binyamin J, et al. 2005. The role of northern lakes in a regional energy balance. Journal of Hydrometeorology, 6(3): 291-305.

Schertzer W M, Rouse W R, Blanken P D. 2000. Cross-lake variation of physical limnological and climatological processes of Great Slave Lake. Physical Geography, 21(5): 385-406.

Schertzer W M, Rouse W R, Blanken P D, et al. 2003. Over-lake meteorology and estimated bulk heat exchange of Great Slave Lake in 1998 and 1999. Journal of Hydrometeorology, 4(4): 649-659.

Small E E, Sloan L C, Hostetler S, et al. 1999. Simulating the water balance of the Aral Sea with a coupled regional climate-lake model. Journal of Geophysical Research: Atmospheres, 104(D6): 6583-6602.

Tsuang B J, Tu C Y, Arpe K. 2001. Lake parameterization for climate models. Report No. 316. Hamburg: Max Planck Institute for Meteorology. Hamburg, Germany, 1-72.

Van der Molen M K, Gash J H C, Elbers J A. 2004. Sonic anemometer (co)sine response and flux measurement: II. The effect of introducing an angle of attack dependent calibration. Agricultural and Forest Meteorology, 122(1-2): 95-109.

Van Dijk A, Moene A F, De Bruin H A R. 2004. The principles of surface flux physics: theory, practice and description of the ECPACK library. Internal Report 2004/1. Wageningen: Meteorology and Air Quality Group, Wageningen University. Wageningen, The Netherlands, 1-99.

Vourlitis G L, Filho N P, Hayashi M M S, et al. 2002. Seasonal variations in the evapotranspiration of a transitional tropical forest of Mato Grosso, Brazil. Water Resources Research, 38(6): 1094.

Walter K M, Zimov S A, Chanton J P, et al. 2006. Methane bubbling from Siberian thaw lakes as a positive feedback to climate warming. Nature, 443(7107): 71-75.

Wang J M, Mitsuta Y. 1990. Peculiar downward water vapor flux over Gobi Desert in the daytime. Journal of the Meteorological Society of Japan, 68(3): 399-402.

Wang J M, Mitsuta Y. 1992. Evaporation from the desert: some preliminary results of HEIFE. Boundary-Layer Meteorogy, 59(4): 413-418.

Wang N A, Ning K, Li Z L, et al. 2016. Holocene high lake-levels and pan-lake period on Badain Jaran Desert. Science China Earth Sciences, 59(8): 1633-1641.

Warner T T. 2004. Desert Meteorology. Cambridge: Cambridge University Press, 136.

Webb E K, Pearman G I, Leuning R. 1980. Correction of flux measurements for density effects due to heat and water vapor transfer. Quarterly Journal of the Royal Meteorological Society, 106(447): 85-100. 
Wever L A, Flanagan L B, Carlson P J. 2002. Seasonal and interannual variation in evapotranspiration, energy balance and surface conductance in a northern temperate grassland. Agricultural and Forest Meteorology, 112(1): 31-49.

Williams M, Malhi Y, Nobre A D, et al. 1998. Seasonal variation in net carbon exchange and evapotranspiration in a Brazilian rain forest: a modelling analysis. Plant, Cell \& Environment, 21(10): 953-968.

Xiao W, Liu S D, Wang W, et al. 2013. Transfer coefficients of momentum, heat and water vapour in the atmospheric surface layer of a large freshwater lake. Boundary-Layer Meteorology, 148(3): 479-494.

Xu Z W, Liu S M, Li X, et al. 2013. Intercomparison of surface energy flux measurement systems used during the HiWATER-MUSOEXE. Journal of Geophysical Research: Atmosphere, 118(23): 13140-13157.

Yang X P, Williams M A J. 2003. The ion chemistry of lakes and late Holocene desiccation in the Badain Jaran Desert, Inner Mongolia, China. CATENA, 51(1): 45-60.

Yang X P, Ma N N, Dong J F, et al. 2010. Recharge to the inter-dune lakes and Holocene climatic changes in the Badain Jaran Desert, western China. Quaternary Research, 73(1): 10-19.

Zhang X C, Gu S, Zhao X Q, et al. 2010. Radiation partitioning and its relation to environmental factors above a meadow ecosystem on the Qinghai-Tibetan Plateau. Journal of Geophysical Research: Atmospheres, 115(D10): D10106.

Zhu B Q, Yang X P, Liu Z T, et al. 2012. Geochemical compositions of soluble salts in aeolian sands from the Taklamakan and Badanjilin deserts in northern China, and their influencing factors and environmental implications. Environmental Earth Sciences, 66(1): 337-353.

Zhu J F, Wang N A, Chen H B, et al. 2010. Study on the boundary and the area of Badain Jaran Desert based on remote sensing imagery. Progress in Geography, 29(9): 1087-1094. (in Chinese) 